\title{
Capacitated vehicle routing problem model for carriers
}

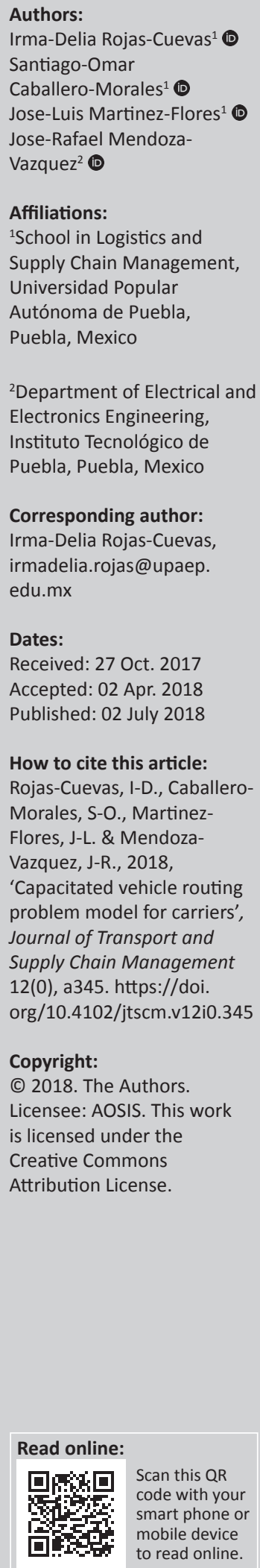

Background: The Capacitated Vehicle Routing Problem (CVRP) is one of the most important transportation problems in logistics and supply chain management. The standard CVRP considers a fleet of vehicles with homogeneous capacity that depart from a warehouse, collect products from (or deliver products to) a set of customer locations (points) and return to the same warehouse. However, the operation of carrier companies and third-party transportation providers may follow a different network flow for collection and delivery. This may lead to non-optimal route planning through the use of the standard CVRP.

Objective: To propose a model for carrier companies to obtain optimal route planning.

Method: A Capacitated Vehicle Routing Problem for Carriers (CVRPfC) model is used to consider the distribution scenario where a fleet of vehicles depart from a vehicle storage depot, collect products from a set of customer points and deliver them to a specific warehouse before returning to the vehicle storage depot. Validation of the model's functionality was performed with adapted CVRP test problems from the Vehicle Routing Problem LIBrary. Following this, an assessment of the model's economic impact was performed and validated with data from a real carrier (real instance) with the previously described distribution scenario.

Results: The route planning obtained through the CVRPfC model accurately described the network flow of the real instance and significantly reduced its distribution costs.

Conclusion: The CVRPfC model can thus improve the competitiveness of the carriers by providing better fares to their customers, reducing their distribution costs in the process.

\section{Introduction}

Transportation is an important part of logistic operations, which is aimed to deliver the goods required by a customer to the right place at the right time. According to Johnson \& Schneider (1995:46), the licensed transportation industry started to grow continuously since 1975; transport deregulation was identified by Bienstock and Mentzer (1999:42) as a reason for this growth in the United States. On the other hand, the licensed transportation industry in Africa began to grow since the middle of the 1990s as a result of the increased competition caused by trade liberalisation and operational costs of trucking (Pedersen 2001:94).

Within this context, costs associated with transportation may represent a significant part of a product's value. Hence, for many companies, physical distribution costs may represent more than 25\% of a product's sales value (Bienstock \& Mentzer 1999:42). In 2014 it was reported by Havenga et al. (2016:9) that transportation cost in South Africa was approximately 57\% (where the fuel cost represented $40 \%$ of the total road transportation cost) of total logistics costs. Hence, in some cases, outsourcing transportation services is an alternative for reducing a company's distribution costs. This can be done by contracting an external transport provider or carrier (Sventekova 2007:II-18-II-20). According to Antoniolli et al. (2015:1), a company can save up to $60 \%$ of its transportation costs by contracting a carrier. In the Netherlands approximately $43 \%$ of transportation activities were outsourced to third-party companies in 2016 (Dutch Logistics Hotspots 2017:1). However, these savings depend on the costs of the carrier, which are closely associated with the efficiency of its route planning. Although the importance of carriers has been recognised, only a few distribution models can be applied to obtain optimal solutions for real problems.

In this regard, a distribution model for route planning, formulated as a Capacitated Vehicle Routing Problem for Carriers (CVRPfC), is proposed to address the distribution scenario of a real situation which has a sequence restriction associated with its delivery and vehicle-storing locations. The proposed model is outlined below through, (1) a literature review within the 
context of distribution models to highlight its relevance, (2) a formal definition and mathematical formulation used for implementation, (3) validation through adapting well-known routing test problems to evaluate its functionality, and (4) the assessment of the economic impact on the real problem.

\section{Literature review}

Currently, there are logistic tools such as Travel Demand Models (TDMs) to support the development of appropriate route plans. Within the TDMs, the Capacitated Vehicle Routing Problem (CVRP) algorithm is an important element. The CVRP is focused on modelling and designing routes that start and end at a single location, which is commonly identified as a warehouse or distribution centre. These routes must serve a finite set of customer locations for collection or delivery of goods. As these routes are served by vehicles of finite capacity, the demands or requirements of the customers to be served must not exceed the capacity of the assigned vehicle (Dantzig \& Ramser 1959:81). Figure 1 presents the general structure of a distribution network modelled by the CVRP for company A that performs all delivery or collection tasks and stores its vehicles at warehouse.

The CVRP has been studied and extended in the literature as a result of its importance for efficient physical delivery of goods and services. Included among the most significant extensions are the following: the Multi-Depot Capacitated Arc Routing Problem with Full Truckloads (Liu et al. 2010); the Multi-Depot Split Delivery VRP (Ray et al. 2014); the CVRP model with fuel consumption optimisation (Xiao et al. 2012); the VRP with Time Windows (Jabali et al. 2015; Savelsbergh 1985); and the three-dimensional loading Capacitated VRP (Junqueira \& Morabito 2015). Also, because of its computational non-deterministic polynomial-time hardness (NP-hard complexity), diverse algorithms have been developed to solve the CVRP to near-optimality. A review of exact algorithms to solve the VRP under capacity and time window constraints is presented by Baldacci, Mingozzi and Roberti (2012). Other solution approaches such as the hybrid algorithm for the VRP with heterogeneous fleet - vehicles with various capacities (Subramanian et al. 2012) - and the algorithm for the cumulative CVRP (Lysgaard \& Wøhlk 2014) have provided additional insights about solution approaches for the CVRP. An updated review of the CVRP and its solution approaches are presented by Braekers, Ramaekers and Van Nieuwenhuyse (2016).

However, most of the CVRP models reported in the literature consider a distribution network like the one presented in Figure 1, where the fleet of vehicles depart and return to a single location (i.e. a warehouse). If company A outsources the distribution task to an external company such as carrier $\mathrm{B}$, the distribution routes may have a different configuration or sequence restrictions. In this case, if the route planning is not efficient, it will be reflected by higher transportation fares of company A.

Although the scenario where the carrier company does not return to the initial point is not addressed by the standard

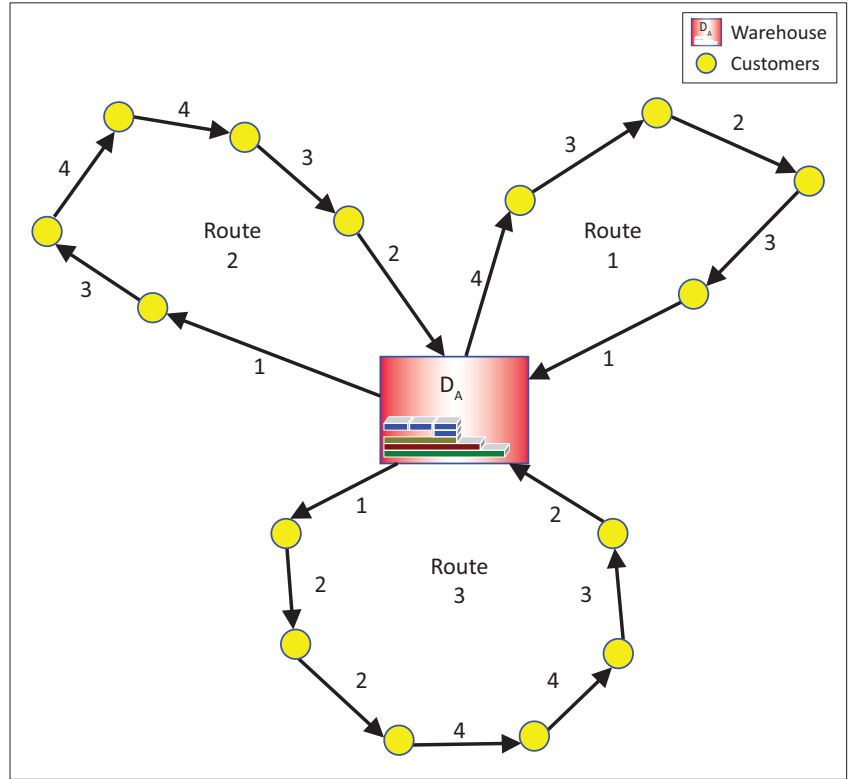

$D_{A}=$ warehouse of company $A$.

FIGURE 1: Example of the Capacitated Vehicle Routing Problem with three routes (served by three vehicles).

CVRP model, an extension known as the capacitated Open Vehicle Routing Problem (OVRP) addresses a similar distribution scenario (Repoussis et al. 2010; Sariklis \& Powell 2000; Schrage 1981). In the OVPR, the vehicles are not required to return to the departure depot as is common for companies when outsourcing their distribution function. Not returning to the departure depot also occurs when the capacity of the fleet (which is owned by company A) is not sufficient to perform all the distribution tasks or when the maintenance of the fleet is too expensive (Liu, Jiang \& Geng 2014; Tyasnurita, Özcan \& John 2017).

The OVRP has been extended, leading to the following alternative formulations: the Multi-Depot OVRP (Lalla-Ruiz et al. 2016; Tarantilis \& Kiranoudis 2002); the OVRP with Multi-Depot Vehicle Routing Problem and Mixed Closed and Open Inter-Depot Routes (Ramos, Gomes \& Barbosa-Póvoa 2013); the OVRP with Heterogeneous Fixed Fleet (HFFOVRP) (Li, Leung \& Tain 2012); the OVRP with Uncertainty in Demand (Cao, Lai \& Yang 2014); and the OVRP with Cross-docking (Yu, Jewpanya \& Redi 2016). In a similar way as the CVRP, the OVRP is also NP-hard; thus, the use of meta-heuristics has been proposed to solve it. However, there are exact methods to solve the OVRP (Barbosa et al. 2010).

As a result of the features of the OVRP, its routes consist of Hamiltonian paths (in graph theory, a Hamiltonian path is a path in an undirected or directed graph that visits each vertex exactly once) that originate at a specific location (e.g. depot or warehouse) and terminate at a different location (e.g. a customer location). In contrast, as presented in Figure 1, the routes of the CVRP consist of Hamiltonian cycles (Hamiltonian paths that are cycles) (Cao et al. 2014; Chen, Dong \& Xiao 2016).

Although the OVRP can be used for carriers, not all carriers operate using the OVRP formulation. Therefore, additional 
models have been developed that provide for the particular features of these real carrier problems.

\section{Problem definition}

The problem discussed in this article can be outlined as follows: The carrier company (company B) is the vehicles' owner and the vehicles are stored in the depot of vehicle storage $\left(\mathrm{O}_{B}\right)$. When a collection service is requested by the contracting company (company A), the carrier's fleet depart from $\mathrm{O}_{B^{\prime}}$, serve the customer locations and then arrive at the contracting company's warehouse $\left(\mathrm{D}_{\mathrm{A}}\right)$ for delivery of all the collected goods. After the delivery is finished, all vehicles return to the carrier's depot $\left(\mathrm{O}_{\mathrm{B}}\right)$.

A graphical representation of the distribution network is presented in Figure 2. As presented, three vehicles depart from the vehicle storage $\operatorname{depot}\left(\mathrm{O}_{\mathrm{B}}\right)$ and each vehicle serves or visits each of its assigned supplier locations only once. All vehicles then arrive at the warehouse $\left(\mathrm{D}_{\mathrm{A}}\right)$ and finally they all return to $\mathrm{O}_{B}$. This leads to the carrier's routes consisting of Hamiltonian cycles and the features of the OVRP do not completely fit the routing characteristics for this carrier. Hence, for this problem, an adaptation of the CVRP model, namely the CVRPfC, is proposed to address this distribution problem.

\section{Model formulation}

The CVRPfC can be formulated as an integer programming (IP) model and an outline of this is given here. The IP formulation of the CVRPfC model considers that if the network consists of $i=1, \ldots, N$ locations (nodes or points) and the vehicle storage depot of the carrier $\left(\mathrm{O}_{\mathrm{B}}\right)$ is located at $i=1$ (first node), then the optimal routing must serve the customer locations $i=2, \ldots, N-1$ to deliver all collected goods at $i=N$ (last node), which represents the location of the warehouse of the contracting company $\left(D_{A}\right)$.

As input data, the IP formulation requires the following, (1) the quantity of vehicles to be used, (2) the vehicles' capacity (in this case a homogeneous fleet is considered), (3) the costs or distances between all location points, and (4) the quantity to be collected at each location (with the exception of $\mathrm{O}_{\mathrm{B}}$ and $\mathrm{D}_{\mathrm{A}}$ ).

In general terms, an IP formulation must consist of the following elements, (1) an objective function, (2) a set of constraints (restrictions), and (3) a set of decision variables (Winston 2005:2). For the CVRPfC model, these elements are the following:

1. Objective function:

$\operatorname{Min} \sum_{i=1}^{n} \sum_{j=1}^{n} C_{i j} y_{i j}+K C_{D O}$

[Eqn 1]

2. Subject to the following constraints:

$\sum_{i \in V} y_{i j}=1, \forall i \in V \mid\{O, D\}, i \neq j$

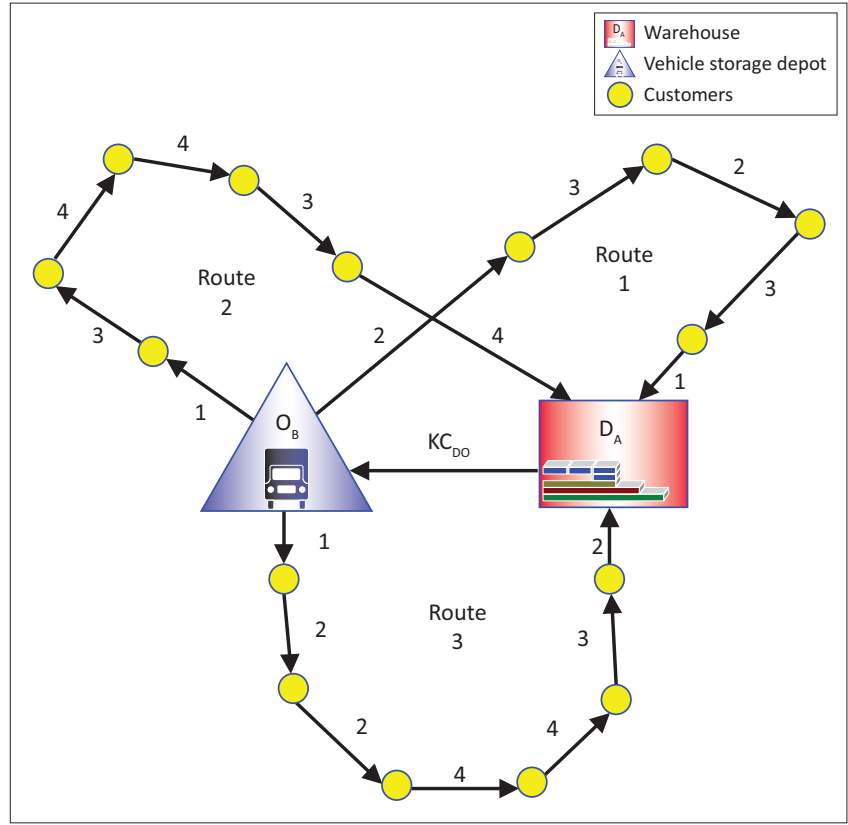

$D_{A}=$ warehouse of company $A ; O_{B}$, vehicle storage depot of company $B ; K C_{D O}=$ return transport cost or distance of all vehicles from $D_{A}$ to $O_{B}$.

FIGURE 2: Example of the Capacitated Vehicle Routing Problem for Carriers with three routes, served by three vehicles of the carrier.

$\sum_{j \in V} y_{i j}=1, \forall i \in V \mid\{O, D\}, i \neq j$

[Eqn 3]

$\sum_{j \in V} y_{O j}=K$

[Eqn 4]

$\sum_{i \in V} y_{i D}=K$

[Eqn 5]

$\sum_{k \in K} x_{O D}^{k}=K$

[Eqn 6]

$\sum_{k \in K} x_{D j}^{k}=0, \quad \forall j \in V, j \neq O$

[Eqn 7]

$U_{i}-U_{j}+q y_{i j} \leq q-d_{j} \quad \forall i, j \in V \backslash\{O, D\}, i \neq j$

where $d_{i}+d_{j} \leq q$

[Eqn 8]

$\mathrm{d}_{\mathrm{i}} \leq \mathrm{u}_{\mathrm{i}} \leq \mathrm{q} \quad \forall \mathrm{i} \in \mathrm{V} \backslash\{O, D\}$

[Eqn 9]

3. Decision variables:

$\mathrm{y}_{i j} \in\{0,1\} \quad \forall i, j \in V$

[Eqn 10]

$x_{i j}^{k} \in\{0,1\} \quad \forall i, j \in V, \forall k \in K$

[Eqn 11]

where:

$i=$ departure location or node

$j=$ arrival node

$k=$ the vehicle to be used $(k \in K)$

$|K|$ = quantity of available vehicles

$V=$ set of collection nodes

$U=$ load of the vehicle

$d_{i}=$ demand of the customer at node $I$

$C_{i j}=$ transport cost or distance from node $i$ to node $j$

$x_{i j}{ }^{k}=1$ if vehicle $k$ is assigned to traverse the arc or path from node $i$ to node $j\left(x_{i j}{ }^{k}=0\right.$ otherwise) 
$y_{i j}=1$ if the route from node $i$ to node $j$ exists $\left(y_{i j}=0\right.$ otherwise)

$q$ = capacity of the vehicle $k$

$O=$ vehicle storage depot $\mathrm{O}_{\mathrm{B}}$

$D=$ delivery node $\mathrm{D}_{\mathrm{A}}$ (warehouse)

$C_{D O}=$ transport cost or distance from $\mathrm{D}_{\mathrm{A}}$ to $\mathrm{O}_{\mathrm{B}}$

$K C_{D O}=$ return transport cost or distance of all vehicles from $\mathrm{D}_{\mathrm{A}}$ to $\mathrm{O}_{\mathrm{B}}$.

The objective function:

Eqn (1) is formulated such that it minimises the total distance or costs of all routes in the collection or delivery network, including the final route from $\mathrm{D}_{\mathrm{A}}$ to $\mathrm{O}_{\mathrm{B}}$.

The constraints represent the following:

Eqn (2) and (3) ensure that each customer is visited or served only once by a vehicle

Eqn (4) ensures that all vehicles depart from $\mathrm{O}_{B}$

Eqn (5) ensures that all vehicles arrive at $D_{A}$

Eqn (6) ensures that no vehicle can travel directly from $O_{B}$ to $D_{A}$ (although all vehicles must travel directly from $D_{A}$ to $O_{B}$ ) Eqn (7) ensures that no vehicle can travel from $D_{A}$ to other nodes or locations (however, all vehicles must arrive at $\mathrm{D}_{\mathrm{A}}$ before travelling to $\mathrm{O}_{B}$ )

Eqn (8) and (9) ensure that the demands of the served locations do not exceed the assigned vehicle's capacity

Eqn (10) and (11) indicate that the decision variables $x, y$ are binary.

\section{Model validation with adapted Capacitated Vehicle Routing Problem Test Problems}

Sets of symmetric CVRP examples were adapted to validate the functionality of the CVRPfC model. The adaptation considered the last demand node as the location of $\mathrm{O}_{B}$. This requires that the demand of this node is set to zero.

The test problems were taken from the Vehicle Routing Problem LIBrary (VRPLIB). This is a compilation of test problems for examples of routing problems (sets of nodes, demands, capacities, etc.) which can be used for testing purposes. This database of test problems is described in Vigo (1999) and Networking and Emerging Optimisation (2012). Particularly, the sets P by Augerat et al. (1998) and E by Christofides, Mingozzi and Toth (1981) were considered. Table 1 presents an overview of these problems.

TABLE 1: Considered Capacitated Vehicle Routing Problem Test Problems for adaptation.

\begin{tabular}{lcccc}
\hline Number & $\begin{array}{c}\text { Test problem } \\
\text { name }\end{array}$ & $\begin{array}{c}\text { Dimension } \\
\text { (nodes) }\end{array}$ & Capacity & Vehicles \\
\hline 1 & E016-03m & 15 & 90 & 3 \\
2 & E016-05m & 16 & 55 & 5 \\
\hline 3 & E021-04m & 21 & 85 & 4 \\
4 & E021-06m & 21 & 58 & 6 \\
\hline 5 & P-n16-k8 & 16 & 35 & 8 \\
6 & P-n19-k2 & 19 & 160 & 2 \\
7 & P-n20-k2 & 20 & 160 & 2 \\
8 & P-n21-k2 & 21 & 160 & 2 \\
9 & P-n22-k2 & 22 & 160 & 2 \\
10 & P-n23-k8 & 23 & 40 & 8 \\
\hline
\end{tabular}

Because Octave is a scientific programming language (Quarteroni, Saleri \& Gervasio 2010:1) that allows one to obtain data from text files, creating algorithms and graphics, it was used in this paper. Firstly, it was used for the extraction of location data from the adapted CVRP examples and therefore to obtain the distances from node $i$ to node $j\left(C_{i j}\right)$ before optimisation via the IP model. Once the results were obtained, they were visualised in different graphs.

Distances between all nodes were put into a distance matrix of size $N \times N$ while $C_{i j}$ was computed as follows:

$C_{i j}=\sqrt{\left(a_{i}-a_{j}\right)^{2}+\left(b_{i}-b_{j}\right)^{2}}$

where $a_{i}$ and $a_{j}$, and $b_{i}$ and $b_{j}$ are the $x y$-coordinates of nodes $i$ and $j$, respectively.

With the data properly prepared, processed and in the correct format, the solution of the CVRPfC could be obtained by using the optimisation software, LINGO.
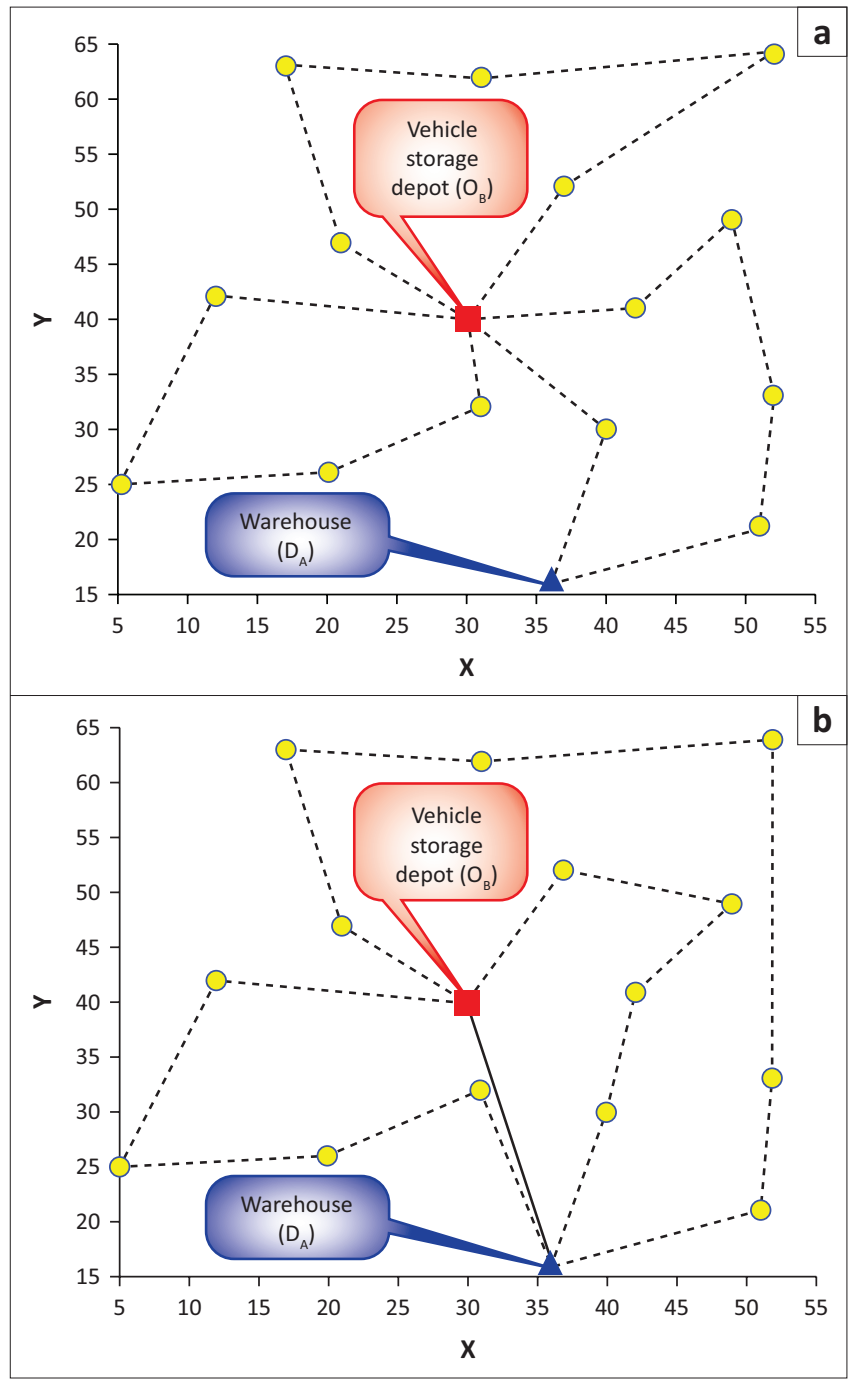

$D_{A}=$ warehouse of company $A ; O_{B}$, vehicle storage depot of company $B$.

FIGURE 3: (a) Capacitated Vehicle Routing Problem (CVRP) and (b) Capacitated Vehicle Routing Problem for Carriers (CVRPfC) - Routing planning with the Capacitated Vehicle Routing Problem and Capacitated Vehicle Routing Problem for Carriers models, for 15 nodes, 3 vehicles and vehicle capacity of 90 units (test problem name E16-03m). 
Figure 3 presents the solution obtained for 15 nodes, 3 vehicles and vehicle capacity of 90 units with the CVRP and CVRPfC models. This test problem consists of 16 nodes (14 collection nodes plus the locations $\mathrm{O}_{B}$ and $\mathrm{D}_{\mathrm{A}}$ at nodes 1 and 16, respectively). As can be seen, with the CVRP model, only one route is used to serve node $D_{A}$ and it does not immediately serve node $\mathrm{O}_{B}$. In addition, the route does not end at node $\mathrm{O}_{B}$ after node $D_{A}$ is served. In contrast, with the CVRPfC model, all routes arrive at node $D_{A}$ before ending at node $\mathrm{O}_{B}$.

Figure 4 shows the routing solutions obtained with the CVRPfC model for all the adapted test problems. As presented, in all adapted cases, the routing scheme is consistent with the requirements of the carrier company as modelled by the CVRPfC.

\section{Model solution and assessment for the real problem}

After validating the model CVRPfC and verifying its functionality, the next step is to obtain the solution for the real problem where company B provides collection and delivery services for company A. Although the transportation fees of company B are within the economic capabilities of company A, these depend on the distribution planning of company B. Figure 5 presents an overview of the collection and delivery locations including the warehouse $\left(D_{A}\right)$ and the vehicle storage depot $\left(\mathrm{O}_{\mathrm{B}}\right)$.

At present, company B performs the distribution without any planning and all locations are served by four routes as shown in Figure 6. This situation has led company B to hire more employees and to pay more maintenance for vehicles, increasing its operational and wage costs.

As a consequence, to afford the increase in operational costs, company $\mathrm{B}$ is considering to renegotiate and to increase the transportation fees for company A. However, this strategy is not recommended as company $\mathrm{A}$ is considering contracting another carrier company $\mathrm{C}$ that is offering transportation services with lower fees. For this reason, recommended strategy for company B would be to improve its operational performance and reduce costs instead of increasing its service fees by using the proposed CVRPfC model.

The first step to achieve this was to obtain the location and transportation data to determine the current status of the carrier in terms of costs. These data were also used with the CVRPfC model to optimise the routes. Tables 2 and 3 present the estimated distances between all locations and the quantities to be collected by the carrier from each location. To obtain a symmetric distance matrix, the availability of two-way routes was verified a priori.

The capacity of each vehicle (van type) is $1000 \mathrm{~kg}$ with the following characteristics: diesel consumption with a performance of $7.05 \mathrm{~km} / \mathrm{L}$ at a cost of $\$ 15.69 / \mathrm{L}$. Based on these data, the estimated consumption costs presented in Table 4 were determined for the current routing scheme.

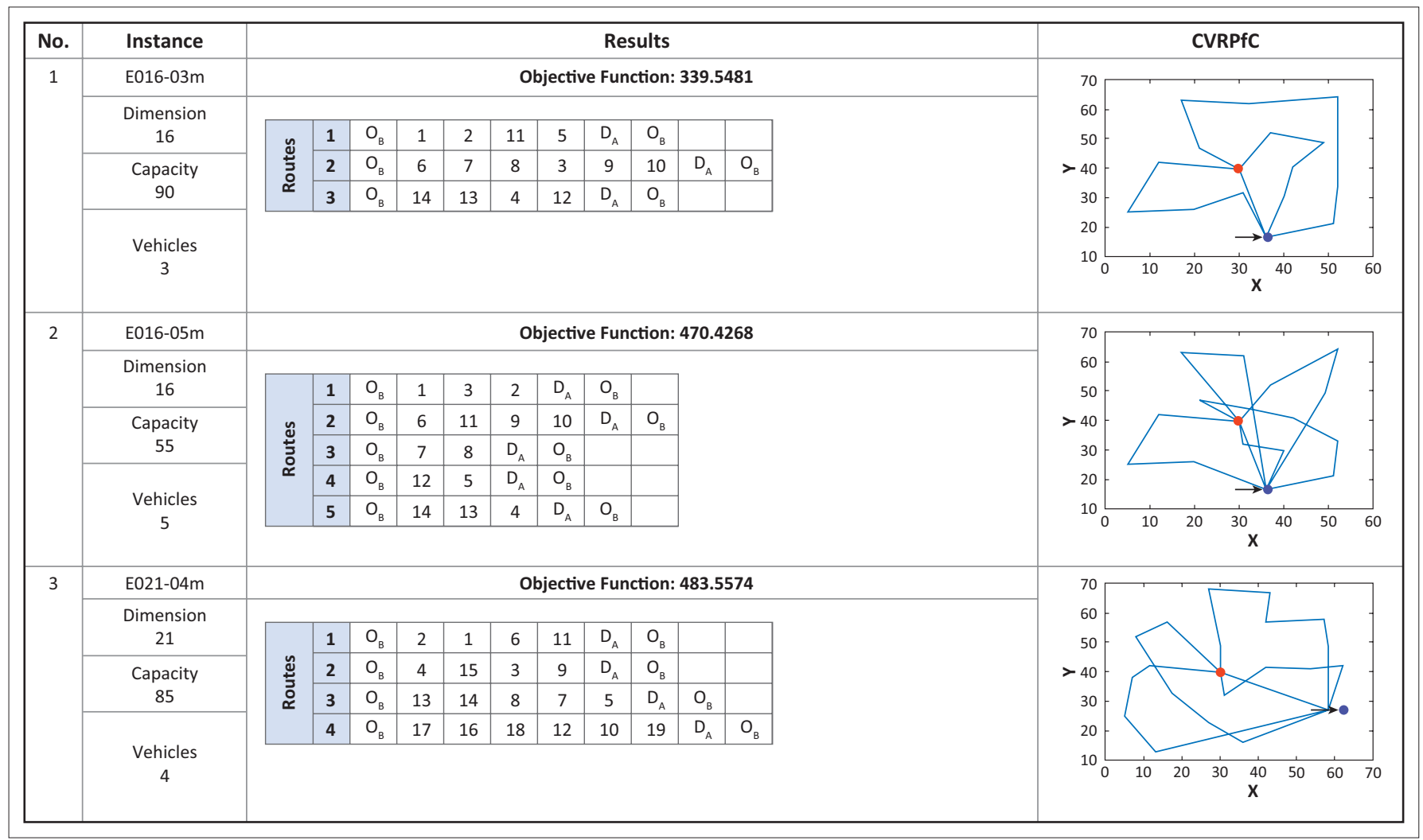

CVRPfC, Capacitated Vehicle Routing Problem for Carriers.

FIGURE 4: Solutions of the Capacitated Vehicle Routing Problem for Carriers model on adapted Vehicle Routing Problem LIBrary test problems. 


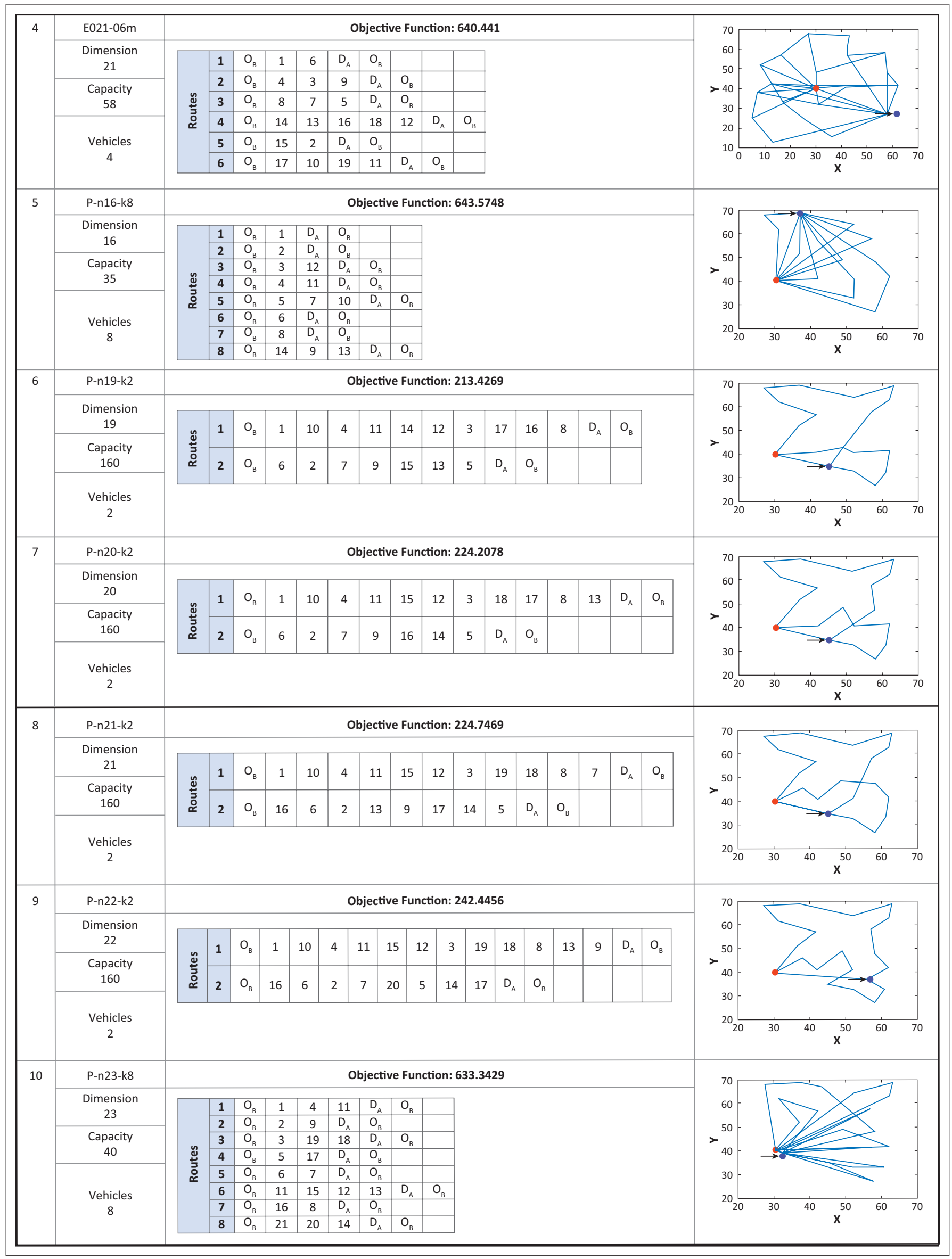

CVRPfC, Capacitated Vehicle Routing Problem for Carriers.

FIGURE 4 (Continues...): Solutions of the Capacitated Vehicle Routing Problem for Carriers model on adapted Vehicle Routing Problem LIBrary test problems. 


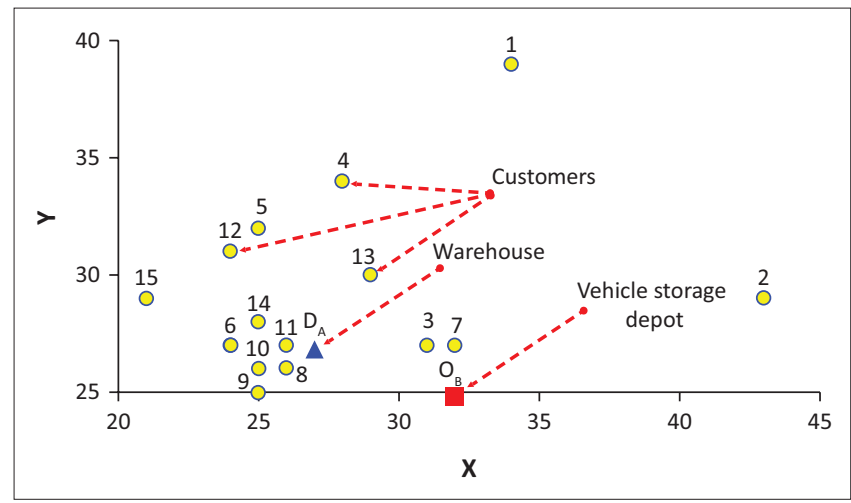

FIGURE 5: Collection, delivery and vehicle storage locations of the real problem.
Having obtained all the required data for the real problem, the next step is to optimise the current routing scheme using the CVRPfC model. The optimised routing scheme as determined by the CVRPfC model is presented in Figure 7.

As presented in Figure 7, only two routes are required to serve all the collection locations for company A. This results in a reduction of $50 \%$ in the quantity of service routes with an associated reduction of the operational and wage costs for the carrier company B. Table 5 presents the updated estimated consumption costs associated with the optimised routing scheme. As presented, a daily saving of $\$ 347.45-\$ 170.17=$ $\$ 177.28$ can be obtained with the optimised routing scheme.

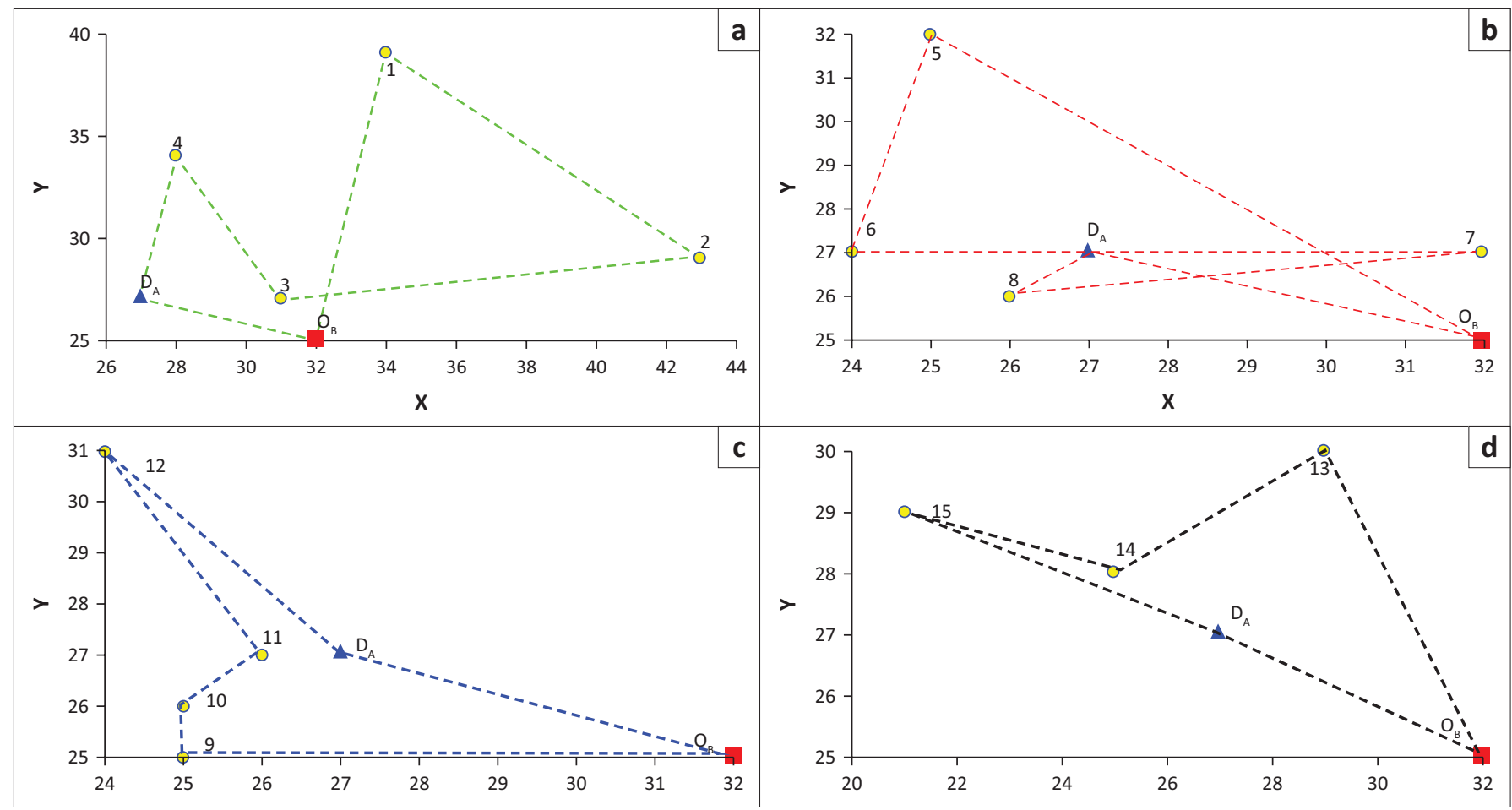

FIGURE 6: Current routes served by company B for the real problem: (a) Route 1, (b) Route 2, (c) Route 3, (d) Route 4.

TABLE 2: Distances between all locations for the real problem $\left(C_{i j}\right.$ data).

\begin{tabular}{|c|c|c|c|c|c|c|c|c|c|c|c|c|c|c|c|c|c|}
\hline Locations & $\mathrm{O}_{\mathrm{B}}$ & 1 & 2 & 3 & 4 & 5 & 6 & 7 & 8 & 9 & 10 & 11 & 12 & 13 & 14 & 15 & $D_{A}$ \\
\hline $\mathrm{O}_{\mathrm{B}}$ & 0.00 & 14.14 & 11.70 & 2.24 & 9.85 & 9.90 & 8.25 & 2.00 & 6.08 & 7.00 & 7.07 & 6.32 & 10.00 & 5.83 & 7.62 & 11.70 & 5.39 \\
\hline 1 & 14.14 & 0.00 & 13.45 & 12.37 & 7.81 & 11.40 & 15.62 & 12.17 & 15.26 & 16.64 & 15.81 & 14.42 & 12.81 & 10.30 & 14.21 & 16.40 & 13.89 \\
\hline 2 & 11.70 & 13.45 & 0.00 & 12.17 & 15.81 & 18.25 & 19.10 & 11.18 & 17.26 & 18.44 & 18.25 & 17.12 & 19.10 & 14.04 & 18.03 & 22.00 & 16.12 \\
\hline 3 & 2.24 & 12.37 & 12.17 & 0.00 & 7.62 & 7.81 & 7.00 & 1.00 & 5.10 & 6.32 & 6.08 & 5.00 & 8.06 & 3.61 & 6.08 & 10.20 & 4.00 \\
\hline 4 & 9.85 & 7.81 & 15.81 & 7.62 & 0.00 & 3.61 & 8.06 & 8.06 & 8.25 & 9.49 & 8.54 & 7.28 & 5.00 & 4.12 & 6.71 & 8.60 & 7.07 \\
\hline 5 & 9.90 & 11.40 & 18.25 & 7.81 & 3.61 & 0.00 & 5.10 & 8.60 & 6.08 & 7.00 & 6.00 & 5.10 & 1.41 & 4.47 & 4.00 & 5.00 & 5.39 \\
\hline 7 & 2.00 & 12.17 & 11.18 & 1.00 & 8.06 & 8.60 & 8.00 & 0.00 & 6.08 & 7.28 & 7.07 & 6.00 & 8.94 & 4.24 & 7.07 & 11.18 & 5.00 \\
\hline 8 & 6.08 & 15.26 & 17.26 & 5.10 & 8.25 & 6.08 & 2.24 & 6.08 & 0.00 & 1.41 & 1.00 & 1.00 & 5.39 & 5.00 & 2.24 & 5.83 & 1.41 \\
\hline 9 & 7.00 & 16.64 & 18.44 & 6.32 & 9.49 & 7.00 & 2.24 & 7.28 & 1.41 & 0.00 & 1.00 & 2.24 & 6.08 & 6.40 & 3.00 & 5.66 & 2.83 \\
\hline 10 & 7.07 & 15.81 & 18.25 & 6.08 & 8.54 & 6.00 & 1.41 & 7.07 & 1.00 & 1.00 & 0.00 & 1.41 & 5.10 & 5.66 & 2.00 & 5.00 & 2.24 \\
\hline 11 & 6.32 & 14.42 & 17.12 & 5.00 & 7.28 & 5.10 & 2.00 & 6.00 & 1.00 & 2.24 & 1.41 & 0.00 & 4.47 & 4.24 & 1.41 & 5.39 & 1.00 \\
\hline 12 & 10.00 & 12.81 & 19.10 & 8.06 & 5.00 & 1.41 & 4.00 & 8.94 & 5.39 & 6.08 & 5.10 & 4.47 & 0.00 & 5.10 & 3.16 & 3.61 & 5.00 \\
\hline 14 & 7.62 & 14.21 & 18.03 & 6.08 & 6.71 & 4.00 & 1.41 & 7.07 & 2.24 & 3.00 & 2.00 & 1.41 & 3.16 & 4.47 & 0.00 & 4.12 & 2.24 \\
\hline 15 & 11.70 & 16.40 & 22.00 & 10.20 & 8.60 & 5.00 & 3.61 & 11.18 & 5.83 & 5.66 & 5.00 & 5.39 & 3.61 & 8.06 & 4.12 & 0.00 & 6.32 \\
\hline $\mathrm{D}_{\mathrm{A}}$ & 5.39 & 13.89 & 16.12 & 4.00 & 7.07 & 5.39 & 3.00 & 5.00 & 1.41 & 2.83 & 2.24 & 1.00 & 5.00 & 3.61 & 2.24 & 6.32 & 0.00 \\
\hline
\end{tabular}

$D_{A}=$ warehouse of company $A ; O_{B}$, vehicle storage depot of company $B$. 
TABLE 3: Collection data from all suppliers for the real problem (kilograms).

\begin{tabular}{|c|c|c|c|c|c|c|c|c|c|c|c|c|c|c|c|}
\hline Variable & 1 & 2 & 3 & 4 & 5 & 6 & 7 & 8 & 9 & 10 & 11 & 12 & 13 & 14 & 15 \\
\hline Kilogram(s) & 120 & 110 & 112 & 118 & 278 & 133 & 178 & 145 & 58 & 87 & 71 & 121 & 90 & 88 & 95 \\
\hline
\end{tabular}

TABLE 4: Current distance (kilometres) and fuel consumption per route for the real problem.

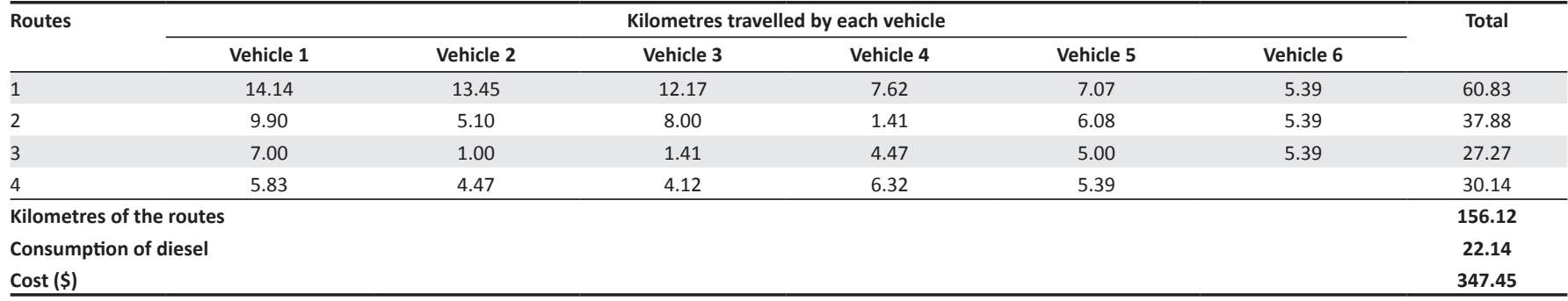
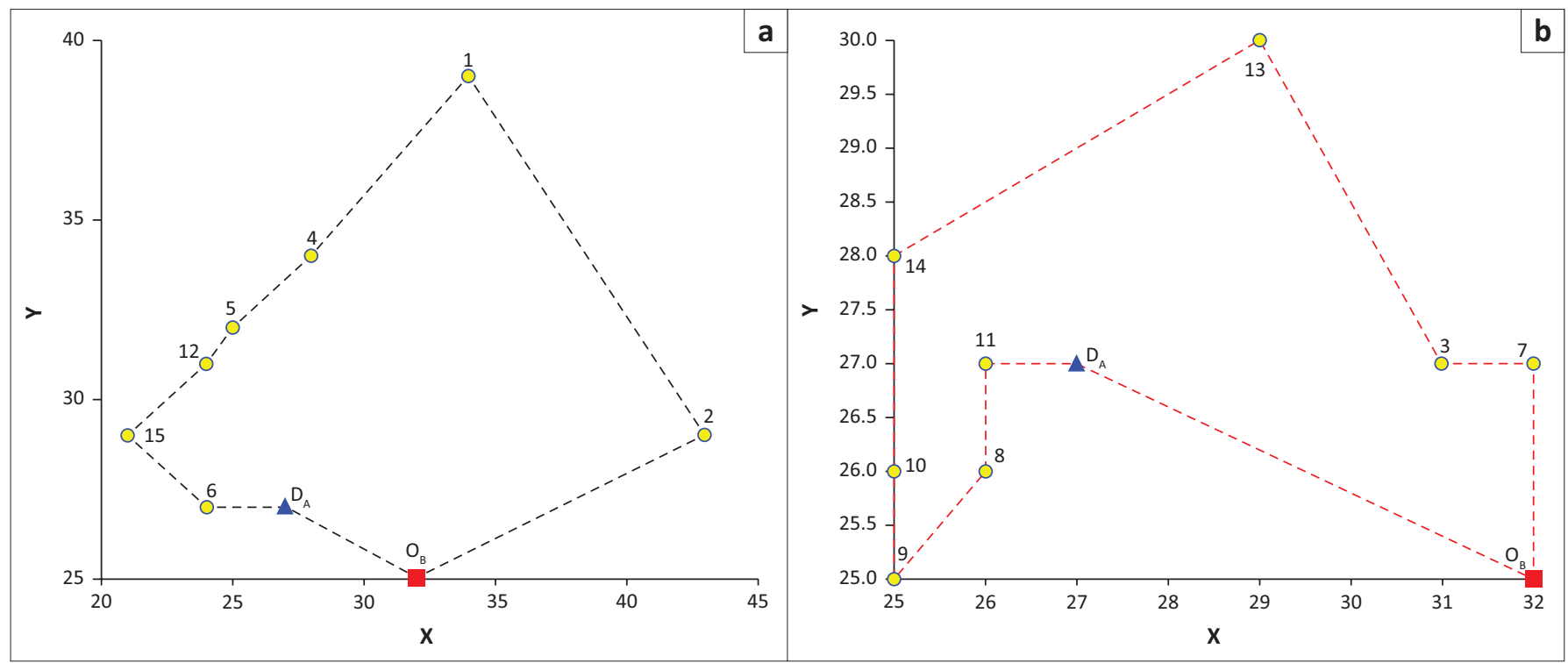

FIGURE 7: Optimised routes served by company B as determined by the Capacitated Vehicle Routing Problem for Carriers model for the real problem: (a) Route 1 and (b) Route 2 .

TABLE 5: Optimised distance (kilometres) and fuel consumption per route for the real problem.

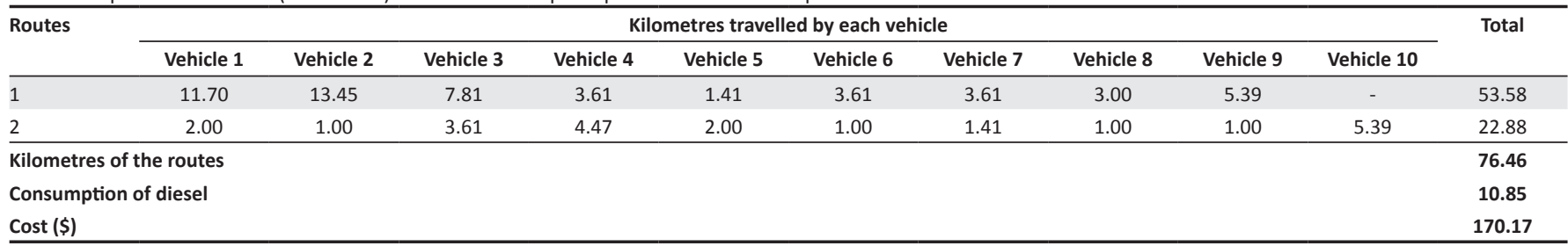

For an annual schedule of 6 days per week, and 52 weeks per year, annual savings of approximately $\$ 55311.00$ can be obtained. These results corroborate the functionality and suitability of the CVRPfC for the carrier.

\section{Conclusions and future work}

In this article, CVRPfC was proposed to obtain a solution for distribution problems in the transportation industry. The CVRPfC model is different from the standard CVRP because it considers a carrier, or third-party, to provide transportation services. Hence, the distribution network considers a specific travelling restriction affecting formulation of the routing scheme, namely collection routes start at the carrier's vehicle storage depot and end at the contracting company's warehouse. However, upon arriving and delivering all collected goods at the warehouse, all vehicles must return to the carrier's vehicle storage depot.

The CVRPfC was formulated as an IP model which was solved by means of the optimisation software package LINGO. To validate and assess its functionality and impact, the CVRPfC was tested on a number of adapted CVRP test problems and one real problem. In all cases, the solutions provided by the CVRPfC model were consistent with the requirements of the considered carrier's distribution scheme.

In particular, for the real problem, the solution of the CVRPfC produced a routing scheme that can significantly reduce the transportation routes and associated operational costs. Savings in transportation costs can enable the carrier to offer 
a lower service fee to the contracting company and achieve a competitive advantage over other carriers.

Future work will be focused on extending the CVRPfC model with other restrictions and decision variables. Among these, the following can be suggested (Eroglu et al. 2014):

- heterogeneous fleet of carriers

- collection or deliveries during specific periods or time windows

- multicapacitated and heterogeneous fleet with multiproducts and split deliveries

\section{Acknowledgements}

The authors would like to thank Universidad Popular Autónoma del Estado de Puebla for their support for this research and publication. The main author would also like to thank Tecnológico Nacional de México/Instituto Tecnológico de Puebla and Consejo Nacional de Ciencia y Tecnología (CONACYT) for their support and the scholarship to pursue a Ph.D. degree.

\section{Competing interests}

The authors declare that they have no financial or personal relationships that may have inappropriately influenced them in writing this article.

\section{Authors' contributions}

I-D.R-C. was responsible for the design, validation, technical review, writing of the article, article format and review of the state of the art. S-O.C-M. was responsible for the review of the article, technical review of the model, corrections of the article, review of article structure, review of English grammar and review of the state of the art. J-L.M-F. was responsible for the review of the article, technical review of the model, corrections of the article and review of article structure. J-R.M-V. was responsible for the initial review of English grammar, initial review of article structure and review of the model.

\section{References}

Antoniolli, P.D., Ferreira, J., Carvalho Jesus, V. \& Camargo Júnior, J.B., 2015, 'Outsourcing of logistics transport: A Brazilian leather industry case study', Forum Outsourcing of logistics
Empresarial 20(2), 1-29.

Augerat, P., Belenguer, J.M., Benavent, E., Corberán, A., Naddef, D. \& Rinaldi, G., 1998, 'Computational results with a branch and cut code for the capacitated vehicle routing', Grenoble, France.: Tech. Rep. 949-M, Université Joseph Fourier.

Baldacci, R., Mingozzi, A. \& Roberti, R., 2012, 'Recent exact algorithms for solving the Vehicle Routing Problem under capacity and time window constraints', European Journal of Operational Research 218(1), 1-6. https://doi.org/10.1016/j.ejor.2011. 07.037

Bienstock, C.C. \& Mentzer, J.T., 1999, 'An experimental investigation of the outsourcing decision for motor carrier transportation', Transportation Journal 39(1), 42-59.

Braekers, K., Ramaekers, K. \& Van Nieuwenhuyse, I., 2016, 'The vehicle routing problem: State of the art classification and review', Computers \& Industrial Engineering 99 300-313. https://doi.org/10.1016/j.cie.2015.12.007

Cao, E., Lai, M. \& Yang, H., 2014, 'Open vehicle routing problem with demand uncertainty and its robust strategies', Expert Systems with Applications 41(7), 3569-3575. https://doi.org/10.1016/j.eswa.2013.11.004

Chen, P., Dong, X. \& Xiao, J., 2016, 'Study on split delivery open vehicle routing problem with two splits', 12th International Conference Natural Computation, Fuzzy System pp. 724-728.

Christofides, N., Mingozzi, A. \& Toth, P., 1981, 'Exact algorithms for the vehicle routing problem, based on spanning tree and shortest path relaxations', Mathematical Programming 20(1), 255-282. https://doi.org/10.1007/BF01589353

Dantzig, G.B. \& Ramser, J.H., 1959, 'The truck dispatching problem', Management Science 6(1), 80-91. https://doi.org/10.1287/mnsc.6.1.80
Dutch Logistics Hotspots, 2017, Logistics Barometer, Colliers International, Amsterdam, Netherlands.

Eroglu D.Y., Gencosman, B.C., Cavdur, F. \& Ozmutlu, H.C., 2014, 'Introducing the MCHF/ OVRP/SDMP: Multicapacitated/Heterogeneous Fleet/Open Vehicle Routing Problems with split deliveries and multiproducts', The Scientific World Journal 2014, 1-14. https://doi.org/10.1155/2014/515402

González Barbosa, J.J., Delgado Orta, J.F., Frairé Huacuja, H.J., Martínez Flores, J.A. \& Morales Rodríguez, M.L., 2010, 'Construcción de una Solución Óptima para un Problema de Asignación de Rutas, Horarios y Cargas del Mundo Real', Computación y Sistemas 13(4), 398-408.

Havenga, J.H., Simpson, Z.P., King, D., De Bod, A. \& Braun, M., 2016, Logistics Barometer South Africa 2016, Stellenbosch University, Stellenbosch, South Africa.

Jabali, O., Leus, R., Van Woensel, T. \& De Kok, T., 2015, 'Self-imposed time windows in vehicle routing problems', OR Spectrum 37(2), 331-352. https://doi.org/10.1007/ s00291-013-0348-1

Johnson, J.C. \& Schneider, K.C., 1995, 'Outsourcing in distribution: The growing importance of transportation brokers', Business Horizons 38(6), 40-48. https:// doi.org/10.1016/0007-6813(95)90086-1

Junqueira, L. \& Morabito, R., 2015, 'Heuristic algorithms for a three-dimensional loading capacitated vehicle routing problem in a carrier', Computers \& Industrial Engineering 88, 110-130. https://doi.org/10.1016/j.cie.2015.06.005

Lalla-Ruiz, E., Expósito-Izquierdo, C., Taheripour, S. \& Voß, S., 2016, 'An improved formulation for the multi-depot open vehicle routing problem', OR Spectrum 38(1), 175-187. https://doi.org/10.1007/s00291-015-0408-9

Li, X., Leung, S.C. \& Tian, P., 2012, 'A multistart adaptive memory-based tabu search algorithm for the heterogeneous fixed fleet open vehicle routing problem', Expert Systems with Applications 39(1), 365-374. https://doi.org/10.1016/j.eswa.2011. System
07.025

Liu, R., Jiang, Z., Fung, R.Y., Chen, F. \& Liu, X., 2010, 'Two-phase heuristic algorithms for full truckloads multi-depot capacitated vehicle routing problem in carrier collaboration', Computers \& Operations Research 37(5), 950-959. https://doi. collaboration', Computers \& Oper
org $101016 /$ j.cor.2009.08.002

Liu, R., Jiang, Z. \& Geng, N., 2014, 'A hybrid genetic algorithm for the multi-depot open vehicle routing problem', OR Spectrum 36, 401-421. https://doi.org/10.1007/ s00291-012-0289-0

Lysgaard, J. \& Wøhlk, S., 2014, 'A branch-and-cut-and-price algorithm for the cumulative capacitated vehicle routing problem', European Journal of Operational Research 236(3), 800-810. https://doi.org/10.1016/j.ejor.2013.08.032

Networking and Emerging Optimization (N.E.O.), 2012, viewed 01 February 2017 from http://neo.Icc.uma.es/vrp/vrp-instances/capacitated-vrp-instances

Pedersen, P.O., 2001, 'Freight transport under globalisation and its impact on Africa', Journal of Transport Geography 9(2), 85-99. https://doi.org/10.1016/S0966-6923 (01)00006-0

Quarteroni, A., Saleri, F. \& Gervasio, P., 2010, Scientific computing with MATLAB and Octave, Springer, New York.

Ramos, T.R.P., Gomes, M.I. \& Barbosa-Póvoa, A.P., 2013, 'Planning waste cooking oil collection systems', Waste Management 33(8), 1691-1703. https://doi.org/ 10.1016/j.wasman.2013.04.005

Ray, S., Soeanu, A., Berger, J. \& Debbabi, M., 2014, 'The multi-depot split-delivery vehicle routing problem: Model and solution algorithm', Knowledge-Based Systems 71, 238-265. https://doi.org/10.1016/j.knosys.2014.08.006

Repoussis, P.P., Tarantilis, C.D., Bräysy, O. \& loannou, G., 2010, 'A hybrid evolution strategy for the open routing problem', Computers \& Operations Research 37(3), 443-455. https://doi.org/10.1016/j.cor.2008.11.003

Sariklis, D. \& Powell, S., 2000, 'A heuristic method for the open vehicle routing problem' Journal of the Operational Research Society 51(5), 564-573. https://doi.org/ 10.1057/palgrave.jors.2600924

Savelsbergh, M.W., 1985, 'Local search in routing problems with time window', Annals of Operations Research 4(1), 285-305. https://doi.org/10.1007/BF02022044

Schrage, L., 1981, 'Formulation and structure of more complex/realistic routing and scheduling problems', Networks 11(2), 229-232. https://doi.org/10.1002/net 3230110212

Subramanian, A., Penna, P.H.V., Uchoa, E. \& Ochi, L.S., 2012, 'A hybrid algorithm for the heterogeneous fleet vehicle routing problem', European Journal of Operational Research 221(2), 285-295. https://doi.org/10.1016/j.ejor.2012.03.016

Sventekova, E., 2007, 'Outsourcing in transportation', Mechanics Transport 3, II-18-II-21.

Tarantilis, C.D. \& Kiranoudis, C.T., 2002, 'Distribution of fresh meat', Journal of Food Engineering 51(1), 85-91. https://doi.org/10.1016/S0260-8774(01)00040-1

Tyasnurita, R., Özcan, E. \& John, R., 2017, 'Learning heuristic selection using a Time Delay Neural Network for Open Vehicle Routing', IEEE Congress on Evolutionary Computation (CEC), San Sebastian, Spain, June 5-8th, 2017, pp. 1474-1481.

Vigo, D., 1999, VRPLIB: A Vehicle Routing Problem Library, viewed 01 February 2017, from http://or.dei.unibo.it/library/vrplib-vehicle-routing-problem-library.

Winston, W.L., 2005, Investigación de operaciones, aplicaciones y algoritmos, International Thomson Editores, México.

Xiao, Y., Zhao, Q., Kaku, I. \& Xu, Y., 2012, 'Development of a fuel consumption optimization model for the capacitated vehicle routing problem', Computers \& Operations Research 39(7), 1419-1431. https://doi.org/10.1016/j.cor.2011. 08.013

Yu, V.F., Jewpanya, P. \& Redi, A.A.N.P., 2016, 'Open vehicle routing problem with crossdocking', Computers \& Industrial Engineering 94, 6-17. https://doi.org/10.1016/j. cie.2016.01.018 